memory formation. In D. Ingle (Ed.), The central nervous system and fish behavior. Chicago: University of Chicago Press, 1968.

Behrend, E. R., \& Bitterman, M. E. Avoidance conditioning in the goldfish: exploratory studies of the CS-US interval. American Journal of Psychology, 1962, 75, 18-34.

Bintz, J. Between and within subject effect of shock intensity on avoidance in goldfish. Journal of Comparative and Physiological Psychology, 1971, 75, 92-97.

Fjerdingstad, E. J. Seasonal changes in goldfish learning? Science, $1974,183,1321$.

Frunkin, K., \& Brookshire, K. Conditioned fear training and later avoidance learning in the goldfish. Psychonomic Science, $1969,16,159-160$.

Scobie, S., \& Fallon, D. Operant and pavlovian control of a defensive shuttle response in goldfish (Carassius auratus). Journal of Comparative and Physiological Psychology, 1974, 86, 858-866.
Scobie, S., \& Herman, B. Detection, reaction, escape, and debilitation thresholds for electric shock in goldfish. Learning and Motivation, 1972, 3, 442-456.

Winer, B. J. Statistical principles in experimental design. New York: McGraw-Hill, 1962.

Woodard, W. T., \& Bitterman, M. E. Classical conditioning of goldfish in the shuttlebox. Behavior Research Methods and Instrumentation, 1971, 3, 193-194.

Woodard, W. T., \& Bitterman, M. E. Pavlovian analysis of avoidance conditioning in the goldfish (Carassius auratus). Journal of Comparative and Physiological Psychology, 1973, 82, 123-129.

Zerbolio, D. J. Temperature-dependent learning in goldfish: a multi-trial active avoidance situation. Behavioral Biology, $1973,8,775-761$.

(Received for publication January 13, 1975.)

Bulletin of the Psychonomic Society

1975, Vol. 5 (4), 347-349

\title{
Individual differences in the ease of imagining the faces of others
}

\author{
J. DON READ and RICHARD H. PETERSON \\ University of Lethbridge, Lethbridge, Alberta Canada T1K $3 M 4$
}

\begin{abstract}
The time required for subjects to imagine the faces of other persons was measured and then correlated with ratings assigned by these same subjects to features (i.e., recency, frequency, emotional involvement) of their interactions with these others. The results demonstrated that the ratings and the imaginal latencies were significantly correlated; however, the relative importance of certain features of the interaction as well as the direction of the relationship varied dramatically from one subject to another.
\end{abstract}

As early as 1883 , Galton (1908) observed individual differences with respect to the ease with which people could recall or visualize the features of friends. Galton regarded these differences as being reflections of the differences in the degree of voluntary control over memory imagery possessed by these individuals. Whereas there is considerable evidence at present to indicate that people do differ reliably along dimensions such as the controllability and vividness of imagery (e.g., Marks, 1972; Richardson, 1972), it is reasonable to assume that intraindividual variability on these dimensions for a variety of stimuli is related to the particular characteristics of that which is being imaged. We decided to follow this line of reasoning a few steps further by developing several dimensions along which personal interactions could be categorized and then trying to

This research was supported by Grant $A 8350$ from the National Research Council of Canada and by University of Lethbridge Grant 71-1069. The authors wish to thank Mark L. Sandilands for his assistance in data analy sis. An earlier draft of this paper was greatly improved by the helpful comments and suggestions of Roger Barnsley, Sam C. Brown, and John T. Hamilton. A portion of this research was presented at the Canadian Psychological Association Meetings, Windsor, Ontario, June, 1974.

Requests for reprints should be sent to J. Don Read, Department of Psychology, The University of Lethbridge, Lethbridge, Alberta, Canada, T1 K 3M4. relate these measurements to the ease of recalling what someone looks like. The three selected for investigation were: emotional involvement, recency, and frequency. Whereas it would be possible to produce differences along these dimensions experimentally, a correlational study was designed in which ease of recall was correlated with each of the dimensions for people already known to the subject. In short, since we have all interacted with others in a great variety of ways and, presumably, the characteristics of these interactions may be recalled, the experiment was designed to take advantage of this wide variety of interaction.

\section{METHOD}

\section{Subjects}

Sixteen second semester psychology students completed the 1-h experiment either for extra class credit or $\$ 3.00$ at their choice.

\section{Materials}

A list of 63 names was constructed such that a wide variety of publicly known figures as well as personal acquaintances for each subject were included. Specifically, the list included relatives, close friends, local celebrities, well known television and movie entertainers, sports figures, and, finally, well known figures in national and international politics. For a number of relatives and 
acquaintances in the list, more than one person could be identified (e.g., uncle, girlfriend); therefore, the subjects were instructed to think "only of one person who fits this description and let this person be your example of that relationship for the remainder of the experiment." Each name was prepared as a slide transparency for projecton purposes.

\section{Design and Procedure}

To correlate the ease of recall with each of the three dimensions chosen, measurements were obtained of each subject's interaction with the stimulus people on each dimension. Therefore, rating scales were developed which would tap the subject's retention of these interactions. Each scale consisted of five categories, and the subject was instructed to place a check in the category which best described his relationship with the stimulus persons on the particular dimension. For the rating of recency of interaction, the subject checked the category best describing the last time he saw the individual named either in person, on T.V., etc. The scale ranged from 1 day to 1 year ago. The frequency of interaction scale was designed to provide an approximate estimate of how often the subject had seen each stimulus person. Thus, the scale ranged from once or twice to very many times. We reasoned that one's strength of feeling about another may also play a role in the ease of recall and, therefore, a final scale was constructed which ranged from no emotional involvement to high emotional involvement. The subjects were instructed to weight their positive and negative feelings equally and were told that their emotional involvements need not be restricted to those individuals with whom they have had personal interaction.

The experiment consisted of three stages. In the first stage, the subjects simply indicated whether or not they had ever seen each of the 63 stimulus people either personally, on television, in movies, magazines, etc. At this point, the subjects were not required to recall what the person looks like but only to indicate whether or not they had ever seen the person. The final two stages consisted of a rating and an image recall task; however, the order in which they occurred depended upon the experimental condition to which the subject was assigned. Marks (1972) has noted that the relationship observed between the vividness and accuracy of imagery is affected by the order in which these two measurements occur because of the expectancies developed by the subjects after one of the tasks. Since the present tasks involve a similar potential for reactivity, the order of the rating and image-recall tasks was counterbalanced across subjects. Thus, for one-half of the subjects, the rating task was completed immediately before the image-recall task and for the remaining subjects, the ratings were completed immediately after the image-recall task. During each rating, the stimulus names were projected at a 5 -sec rate by a Carousel projector on a translucent screen mounted directly in front of the subject. All stimuli were rated on one scale before rating on another; however, the order in which the names appeared varied according to random sequences. The scales were presented in the same order for each subject as follows, recency of interaction, emotional involvement, and frequency of interaction. Only those stimulus names which had been checked by the subject during the first stage were included in the rating task.

During the image-recall or image-generation task, the time taken to recall what someone looks like was measured. These measurements are hereafter referred to as image latencies. As in the rating task, the names were shown to the subject according to a random sequence and a microswitch lever, when released, stopped a time clock which provided a measurement of image latency. At the beginning of each image-recall trial, the subject depressed the lever which activated the projector and time clock; release of the lever turned both units off. The instructions to the subjects emphasized that, whereas the images generated of other may vary considerably in clarity or vividness, it was important to attempt to obtain as clear an image as possible for each name presented.

Finally, a postexperimental inquiry was used to collect information on the vividness of imagery as related to specific people, the steps the subject took in order to generate an image, as well as the completeness and constancy of the imagery experiences.

\section{RESULTS}

The numbers of people checked by the subjects as having been seen before varied across the subjects from 21 to 53 with a mean of 40.0 . For each subject, the ratings assigned on the variables of emotional involvement, recency, and frequency were given a value from 1 to 5 . In view of the ordinal scale data produced by the rating scales, the Spearman rho rank-order correlation coefficient was considered most appropriate for the data analysis. However, since large numbers of tied ranks existed in the rating data, the correction procedure of computing Pearson product-moment correlation coefficients as recommended by Ferguson $(1971$, p. 307) was followed. These coefficients are presented in Table 1. Since the degrees of freedom for each coefficient varied from one subject to another, direct comparisons of the magnitude of the coefficients may not be made and, accordingly, significance values are reported for each coefficient. To begin with, inspection of Table 1 did not reveal a consistent difference either in terms of the magnitudes or directions of the obtained coefficients for the experimental groups. Thus, at a minimum, the results of the two groups did not appear to be affected differentially by the order of testing (i.e., subject's expectancies).

As may be seen in the first column of Table 1, there were nine significant correlations obtained between emotional involvement and image RT, seven were negative and two were positive. In other words, when the two variables were reliably related to one another, the majority of the subjects had shorter latencies for individuals with whom they felt highly involved. However, this relationship was exactly reversed for the remaining two subjects. The six significant correlations obtained between image latency and recency were more consistent in directon than those for emotional involvement but were fewer in number. Thus, for these subjects, the more recent their interaction with the person imaged, the shorter the time required to imagine what the person looked like. Based upon research concerning the probability of recall of verbal materials as a function of retention interval, one would certainly have anticipated the direction of this relationship. Finally, there were 11 significant correlations obtained between image latency and frequency of interaction and, of these, nine were negative and two positive. Clearly, for the majority of these subjects the more frequently they reported having seen a stimulus person, the easier it was to recall what the person looked like. For the 
remaining two subjects, the opposite relationship existed.

In addition to the correlations reported in Table 1, correlation coefficients were computed between each pair of rating variables for each subject. Of a total of 48 coefficients, 36 were statistically significant. In other words, all three variables reflected a more general factor of familiarity. The more involved the subject was with a particular person, the more likely it was that the person had been seen very recently and/or very frequently by the subject.

The responses collected during the postexperimental inquiry indicated that the subject's subjective experiences of image generation were generally in agreement with the image-latency data. Specifically, subjects reported that their most vivid images were experienced for the persons with whom they were highly involved or with whom they had had recent or frequent interaction. Similarly, subjects reported that for these individuals, they often attained a clear, full-face, and relatively unchanging image as opposed to the presence of only one or two prominent facial features and/or an inability to maintain the image for any length of time for individuals with whom there had been less involvement or less frequent or recent contacts. Thus, it appears from these subjective reports that the vividness of facial imagery varies considerably for each subject and that the facial image need not be complete in order to be accepted by the subject as the target person. A final question was designed to provide information about how subjects though they had retrieved an image or the steps taken while attempting to imagine someone's face. There proved to be general agreement among the subjects that for the majority of names presented, they first had to recall either a recent personal interaction, or a movie, photograph, or television show in which the person appeared. In other words, some additional information like an event, location in time, or a picture had to be recalled prior to the attainment of an image. From these reports, it appeared that some general memory "location" had to be reached first before specific imaginal material could be retrieved. Following the location of such information, subjects were not at all clear as to how the facial image was attained; often it seemed to be suddenly evident, or the image had to be gradually constructed from facial features or the subject could somehow "focus" a fuzzy image into a much clearer one. Neither of these introspective reports of the imaging experience itself may be taken as revelations of the structures or contents of memory; however, they perhaps reflect the relationships which exist between these contents.

\section{DISCUSSION}

The results demonstrate that the amount of time required by subjects to imagine the face of another depends upon the extent of the subject's contact with that person. However, the relative
Table 1

Pearson Product-Moment Correlations Between Image Latency and Each Interaction Variable

\begin{tabular}{llll} 
Subject & \multicolumn{4}{c}{$\begin{array}{c}\text { Emotional } \\
\text { Involve- } \\
\text { mumber }\end{array}$} & df & Recency & Frequency \\
\hline
\end{tabular}

Experimental Condition: Before

$\begin{array}{lllll}1 & 31 & -.05 & .32 * & -.51^{* *} \\ 2 & 19 & .39 & .26 & .25 \\ 3 & 37 & -.31^{*} & .24 & -.44^{* *} \\ 4 & 44 & -.46^{* *} & .38^{* *} & -.51^{* *} \\ 5 & 50 & -.41^{* *} & .53^{* * *} & -.48^{* * *} \\ 6 & 32 & .01 & -.01 & -.02 \\ 7 & 41 & .18 & -.01 & .19 \\ 8 & 45 & .13 & .17 & .53^{* * *}\end{array}$

Experimental Condition: After

\begin{tabular}{lllll}
1 & 45 & -.27 & .25 & $-.53^{* * *}$ \\
2 & 41 & $-.55^{* * *}$ & .11 & $-.61^{* * *}$ \\
3 & 51 & $.35^{* *}$ & .17 & $.27 *$ \\
4 & 48 & -.21 & $.43^{* *}$ & -.25 \\
5 & 25 & $-.60^{* * *}$ & $.64 * * *$ & $-.59 * * *$ \\
6 & 43 & $.39 * *$ & .20 & .22 \\
7 & 46 & $-.28 *$ & .03 & $-.30^{*}$ \\
8 & 42 & $-.74^{* * *}$ & $.67 * * *$ & $-.77^{* * *}$ \\
\hline${ }^{*} p$ & $<.05$ & & $* * p<.01$ & $* * * p<.001$
\end{tabular}

importance of certain features of that interaction (i.e., emotional involvement, recency, and frequency) as well as the direction of the relationship varies dramatically from one subject to another. Three subjects produced significant correlations which were opposite in direction to the relationships observed for another nine subjects (i.e., on the variables of emotional involvement and frequency). In this connection, it is also interesting to note that, for many subjects, the time required to imagine what they themselves looked like was considerably longer than that obtained for any of their personal acquaintances. One possibility, of course, is that an attempt is made to greatly increase the quality of the image of oneself or, for the three subjects discussed above, of those with whom they have interacted often or are emotionally involved. As a consequence, longer latencies would be expected. However, other investigators have observed that longer image latencies are associated with lower ratings of vividness within individual subjects (e.g., Neisser $\&$ Kerr, 1973; and indirectly, Marks, 1972) and, therefore, the generation of an image of greater vividness seems unlikely in the present situation. Similarly, reports by the majority of subjects, including the three discussed above during the postexperimental inquiry, indicated that their most vivid images were those which were obtained with relatively short latencies. Thus, image latency appears to be a measure of both the ease of image retrieval or generation and the vividness of the resulting images.

\section{REFERENCES}

Ferguson, G. A. Statistical analysis in psychology and education. 3rd ed. New York: McGraw-Hill, 1971.

Galton, F. (orig. publ. 1883) Inquiries into human faculty. London: Dent, 1908.

Marks, D. F. Individual differences in the vividness of visual imagery and their effect on function. In P. W. Sheehan (Ed.), The function and nature of imagery. New York: Academic Press, 1972.

Neisser, U. \& Kerr, N. Spatial and mnemonic properties of visual images. Cognitive Psy chology, 1973, 5, 138-150.

Richardson, A. Voluntary control of the memory image. In P. W. Sheehan (Ed.), The function and nature of imagery. New York: Academic Press, 1972.

(Received for publication January 21, 1975.) 